\title{
Thai Likay: The Development of an Acting Performance Model in Central Thailand
}

\author{
Tanomsri Seangtong ${ }^{1}$, Songkoon Chantachon ${ }^{1} \&$ Manop Wisutthiphaet ${ }^{2}$ \\ ${ }^{1}$ The Faculty of Cultural Science, Mahasarakham University, Khamriang Sub-District, Kantarawichai District, \\ Maha Sarakham, Thailand \\ ${ }^{2}$ Faculty of Fine Arts, Srinakharinwirot University, Bangkok, Thailand \\ Correspondence: Nuengruethai Coulson, 391/12 Moo 5, Nongchang Sub-District, Nongchang District, Uthai \\ Thani, Thailand. E-mail: david.coulson.6@gmail.com
}

Received: January 17, 2013 Accepted: February 17, 2013 Online Published: March 28, 2013

doi:10.5539/ass.v9n4p194 URL: http://dx.doi.org/10.5539/ass.v9n4p194

\begin{abstract}
Likay is the most important drama in central Thailand; a mixture of Thai traditional and classical arts. The growth of science and technology has influenced value for audiences and the survival of Likay. This is a study of central Likay history, current conditions, acting performances and their identities. The research focuses on the problems with current Likay performances and develops guidelines for improving acting performances to enhance community economy and add value to society and culture. This acting performance model for Likay in Central Thailand will help to ensure the continuation of this priceless art-form.
\end{abstract}

Keywords: Likay, acting performance, development, Central Thailand, cultural value, economic value, social value

\section{Introduction}

There are many types of Thai classical performing art that have been transferred from ancient generations to their descendents continuously for many hundreds of years. Thai classical performing arts can be divided into two groups. The first group is formal and the second is informal. The formal arts were initiated in the royal palaces for the king and the royal members of his household but the informal arts were local shows for the general people. Several Thai performing arts have been changed and modified by the times and have become the new kinds of performing art that are currently found throughout Thailand. The ancient wisdom remains an integral part of the performances and is a national identity that must be conserved.

Likay is a kind of local Thai acting performance that, depending on definitions, began at the end of the Ayutthaya Era or the beginning of the Rattanakosin Era. Likay was modified from the Persian word Sikir and the Arabic word Sikru, which meant reading of hymns for the god of Islam. The Muslims from Persia transferred this performance into Thailand via Indonesia and Malaysia in a continuous process from circa 1259 to 1767AD. This performance used only Islamic rituals until the reign of King Rama II. Likay, then called Dikay, was taken into the royal place as a show for the king. From this point, Likay was included in the meritorious deed performances started by the king. In the reign of King Rama V, Likay became famous due to the beautiful voices of the vocalists. Previously, Likay had been performed only in the Islamic style, but by the reign of King Rama V, Likay had been changed and modified by the local cultures and languages in Thailand and performed in the Thai style. The name was also modified from Dikay, to Yikay, and finally Likay. Thus, Likay became a famous Thai acting performance presenting Thai classical drama or Thai local tales.

When the culture of the big cities was transmitted to the surrounding areas, the conditions of local culture and the lifestyle of local people changed. Likay was not unaffected. Traditional entertainment, including Thai classical performances, was replaced as primary entertainment by modern devices such as television, cinema and radio. So, Likay and other kinds of local performance have decreased in popularity. For this reason, Likay has been adapted to maintain popularity and continue existence. The relevant changes of Likay are about the performance of stories, costumes, music and stage management. These changes are very important for Thai classical performances.

Likay in Central Thailand was very famous until 1917, when its popularity waned under the influence of world 
wars and modern entertainment. While Likay in Central Thailand was fading out, Likay in the countryside was growing, as the modern devices were still rare. The local versions of Likay were easier to understand and had more variety. After the end of World War II, the Thai culture revolution was in full flow, as stated by Field Marshal Por Piboonsongkram, the prime minister at that time. Likay was called Nata Dontree (acting performance with music). Likay was changed and modified again and again and became a Thai performing art with little relation to its Islamic origin. It became more involved with Thai people, lifestyle and tastes and reflected only some aspects of Islamic culture.

Each Likay performance must use a large group of actors and actresses who pass very serious tests and training courses about acting, dancing and singing over a number of years. Most of them are common people and some are heirs of Likay families. The income of Likay performers can be divided into two types. First is the wage from a job contract and second is special money from the audience (a form of tip).

In 1890-1891, Likay was transferred to the common people. At this time the actors or actresses were required to sing, dance and narrate the drama by themselves. In each show, the rammana (a kind of small drum) was replaced by the traditional music band consisting of many Thai classical musical instruments. For this reason, Likay resembled an entertainment show rather than a religious activity. Moreover, the Likay groups were supported by governmental noblemen to have a stable place for their shows. These were called Wig Likay or Rong Likay. Before the show, tickets would be sold in front the stage to interested people. The first famous Wig Likay performance at that time was named Wig Likay Praya Pethpranee and was held in front of Rajanadda Temple from 1896 to 1898. During the reign of King Rama V, Likay usually took place in the casinos. The casinos became illegal during the reign of King Rama VI.

During the reign of King Rama V, the Bangkok community consisted of several ethnicities such as Arabian, Western European, Cambodian and Chinese. So, Thai cultures blended and exchanged with others. Likay was also unavoidably impacted by this influence. Likay was therefore performed in several languages and styles. The aim of each show was purely to entertain the people. Sometimes folk fairytales or famous dramas of other cultures were composed in the show. Moreover, shows about ethnic parodies were performed by Thai actors and became popular, generating more income for the Likay troupes.

The reign of King Rama VI until that of King Rama VII (circa 1911-1977) was the golden era of Likay in Thailand. Likay had been thoroughly developed and had become the most famous entertainment performance. Likay could be found everywhere throughout Thailand. Moreover, Likay was involved with and influenced Thai people in both Bangkok and the countryside. Likay became an important part of contemporary Thai culture.

Nowadays, Likay performers do not enjoy constant careers because of modern culture from the West and the economic situation. According to observations, the researchers found that there are about one thousand Likay groups in Thailand. In six provinces of Central Thailand, consisting of Nontaburi, Pratum Thani, Ayutthaya, Angthong, Singburi and Supanburi, one hundred and twenty-nine can be found. There are more than ten thousand people who work with the Likay groups. The importance and value of Likay is related to Thai culture, traditions and history. So, Likay should be conserved and supported by everyone.

Western cultural influence and economic crisis are the major causes of the Likay development. Nowadays, Likay identity has been changed and blended with other cultures. The researchers were concerned that Likay may fade out or lose its traditional identity in the near future. Thus, the researchers studied an approach to developing Likay performing patterns in order to determine guidelines of Likay conservation and to add economic value to Likay shows. Moreover, the results of this research will be useful evidence for further research.

\section{Research Aims}

This research had three primary aims: a) to study the background and identity of acting performances of Likay in Central Thailand; b) to study the current problem conditions and development approach of Likay in Central Thailand to add economic, social and cultural value; c) to develop patterns of Likay performance in Central Thailand.

\section{Research Methodology}

This was a qualitative research. The researchers focused on nine compositions of Likay performance: belief and rituals, stage and background, music, performers, costumes, story and narration, languages, singing, dancing, and management development. The research data was collected in six provinces of Central Thailand, consisting of Nontaburi, Pratum Thani, Ayutthaya, Angthong, Singburi and Supanburi. In each province, just one Likay troupe was included in the research. The population of this research was comprised of Likay troupe members in the six aforementioned provinces. The informants consisted of people working in the troupes or those involved with 
Likay performances, such as musicians, actors, actresses, and the audience.

The sample was selected using several methods. There were two hundred and twelve people included in this research. All of them were divided into three groups. There were thirty two key informants chosen by snowball sampling and purposive sampling. The key informants were experts in Likay performance and had been involved with Likay performance management for a long time. Ninety casual informants were selected by purposive sampling. Casual informants were Likay troupe members or Likay performers and leaders of nearby communities. A further ninety people were used as general informants and selected by purposive sampling. General informants consisted of Likay audience members, Likay employers and Buddhist monks.

Five types of research tools were used to collect the research data. These were basic survey, structured interview, participant and non-participant observation, focus group discussion and work shop. Data was found by reviewing and searching previous research reports, primary and secondary evidence and textbooks. Additional data came from the aforementioned research tools. Data from reviewing primary or secondary evidence and other previous research was classified into several groups depending on content. The classified data was categorized for ease of analysis. Data validation and verification methods consisted of data triangulation, investigator triangulation, theory triangulation and methodological triangulation. Two further methods of data analysis were employed. These were analytic induction and typological analysis. Finally, the data was presented by descriptive analysis.

\section{Results}

\subsection{Background and Identity of Likay Performances in Central Thailand}

Likay is a kind of acting performance mixed with music and performed on stage. The original Likay was performed during Islamic religious activities. Likay was imported into Thailand through the southern regions during the Ayutthaya era (from about 1259-1767). Likay was then continuously developed and modified until it resembled the current form of Likay. Likay is more popular in Central Thailand than in other regions, especially in the six provinces of Nontaburi, Pratum Thani, Ayutthaya, Angthong, Singburi and Supanburi.

According to the analyzed data collected from six Likay troupes in the six provinces in Central Thailand, the researchers found that evidence of Likay performance dates back more than six-hundred years. Its specific identity is the most important thing maintaining Likay performances. Moreover, Likay has been inherited from generation to generation by the Likay performers and the leaders of each Likay troupe. So, Likay in each community has its own specific identity.

There are nine aspects concerning the identity of each Likay troupe. The researchers found that the identity of each troupe was similar and the performing instructions were also comparable.

\subsubsection{Belief and Rituals}

Each Likay troupe must be concerned with maintaining continuous belief and important rituals of the Likay performance. The relevant rituals consist of the Likay teacher salutation, Rum Tawaimue or 'hand-dancing' on the stage and Ork Keak or 'opening show' of Likay.

\subsubsection{Stage, Light, Colors and Sound}

Each Likay troupe has their own stage, sound system, light system and music band. So, the appearance of Likay staging and other compositions between groups are quite different.

\subsubsection{Music}

The music bands of each Likay troupe also have the same set of five Thai musical instruments. The music or sound tracks used to compose the Likay show would be the same as the traditional style and must be related to the scenes.

\subsubsection{Performers}

The number of performers in each show depends on the story of the show but the major characters consist of a hero or leading actor, a heroine or leading actress, the king and the queen, jokers and villains. Sometimes, five minor female and five minor male characters must be used. The leader of each party would decide to fix the role of each character depending on ability and suitability of the performer.

\subsubsection{Costumes}

The costumes must be related to the character. The costumes can tell the audience about the status or importance of each character. The performers must buy their own fitted costumes, so most costumes are personal performance equipment that cannot be shared with others. The patterns and styles of the costumes also depend on each character but do not differ from the traditional style. All of the costumes must be colorful, sparkling and 
expensive.

\subsubsection{Story and Narration}

Most Likay performances retell old dramas or traditional tales that have been played since ancient times. However, some new scenes would be added to make the show more interesting and more fun.

\subsubsection{Languages}

Local languages of each Likay troupe community have been used in the shows. The conversation of the characters is easy to understand and relates to the mood of each character. The royal language has been used for royal characters in some stories.

\subsubsection{Singing}

Likay performers usually speak or sing in specific rhythms that sound like the rhythms of prose or poetry. The conversation and lyrics have been copied from old literature. So, for different Likay troupes performing the same story, the songs in the show would have the same lyrics but the style or accent might differ.

\subsubsection{Dancing}

Dancing is choreographed to accompany the singing in the show but is not the major focal point. However, every character must be able to dance, especially general dancing and basic movement. The appearance of dancing must also be related to the mood of each character. The quantity and quality of each character's dancing also depends on the troupe policy.

\subsection{Current Problems and Approach to Likay Development in Central Thailand to Add Economic, Social and Cultural Value}

\subsubsection{Problems Restricting Economy}

The quantity of Likay performers is low. This career is not very popular and society does not support Likay as in the past. The new generations do not want to be Likay performers. Moreover, Likay troupe members cannot make enough money to feed themselves. There is a lack of understanding about the beliefs and rituals of Likay culture, which has caused the decline of Likay. There is also a lack of good economic policy from the Likay leaders, which has a great impact on the earned income of the troupe.

\subsubsection{Problems Restricting Society}

Some performers ignore the practice of performance development. Some of the new performers do not want to be professional performers. Some performances lack authentic and creative shows. Some performances are not concerned about social impact and moral expression. They have no new and interesting gimmicks.

\subsubsection{Problems Restricting Culture}

Professional Likay performers have not been supported as role models for the new performers. Likay inheritance is not spread widely and the approach is unclear. Most Likay performances also lack creativity and are not concerned about traditions and culture.

\subsubsection{Likay Performance Development Approach to Add Economic Value}

The local governors and the leader of each community generate a system to help and support Likay to be an acceptable national performing art of Thailand. The new gifted performers are supported to become famous and Thai children are educated about Likay. Likay contests or other kinds of similar activity are organized by the government. Likay is supported as a community business that can earn more income. The Likay troupe management is controlled and managed under good governance strategy.

\subsubsection{Likay Performance Development Approach to Add Social Value}

Performer discipline is fixed and can be used to ensure that old performers can be role models for new generations. Likay performances are able to entertain people and give people some moral idea at the same time. The leader of each troupe is a good role model for the members. The stories or novels used in the show reflect some goodness to the audiences.

\subsubsection{Likay Performance Development Approach to Add Cultural Value}

The government and the leaders of each community support and promote Likay to be an acceptable national performing art. Each community inherits and regulates the traditional Likay performances systemically and continuously. Likay is accepted at local and national levels. The traditional beliefs and rituals of Likay are protected and the other identities of Likay are continued creatively. Likay is also considered a part of national 
cultural heritage.

\subsection{Development of Likay Performance Patterns in Central Thailand to Add Economic, Social, and Cultural Value}

There are a number of areas in the proposed model to develop Likay. Firstly, Likay artists are developed as professionals and supported as role models in each community. Next, there are nine suggested developments for the components of the performance: a) the Likay rituals are useful and meaningful; b) stage, light and sound settings are magnificent and have more available alternatives; c) music bands are standardized and developed continuously; d) actors and actresses have their own identities; e) costumes are suitable for the characters, beautiful, valuable and marvelous; f) the drama is interesting, creative, fun and useful; g) the language is a standard language that can be a good language model; $h$ ) songs and conversations are composed of authentic poems that are beautiful and full of emotion; i) dancing uses standard postures that are beautiful and related to the songs.

In order to add economic value, Likay is considered an occupation, a business and generates more income. In order to add social value, performances give some moral ideas, supply social role models and provide a conformed authentic entertainment experience. In order to add cultural value, artists and performances are creative, traditional rituals should be conserved and Likay becomes a part of the national cultural heritage. Finally, management is developed by basing the structure on meritocratic principles within a community business.

\section{Discussion}

According to the research data, the development of Likay from an Islamic prayer to a famous Thai acting performance on the stage can be described by the Cultural Diffusion Theory. A culture that can be diffused to another must be composed of five innovations, which are relative advantage, compatibility, less complexity, divisibility and visibility. When one culture is diffused into another it means that the two can be mixed and modified together by the local people. There are five things that the local people use to identify whether the new culture is acceptable or not: a) cultural awareness; b) interest; c) evaluation; d) trial; e) adoption or reflection (Branett, 1953). After Likay was imported to Thailand, Likay was changed and modified by local Thai people little by little and then Likay completely became a Thai performing art. Moreover, the researchers found that Likay in each province has its own style that differs from other areas depending on local culture, society and context (Chumchengrak, 1989).

The researchers found that Likay is not only a kind of art but Likay is also an important component of Thai lifestyle. So, Likay performances can increase the value of society and also reflect that value. Likay became a symbolic memory about traditional Thai performing arts and fictive kinship of people in their own community. Likay troupes not only portray a kind of art but also aesthetics and Thai lifestyle. So, the background of Likay can also reflect the background of Thai lifestyle (Kachaprasert, 2000).

Likay continues in Central Thailand because Likay can maintain and conserve the traditional concepts. Likay remains useful for the community and has influence on the society, economy and culture of each community. These research results are related to the structural functionalism theory that mentioned the relationship of society and social environment. Thus, Likay stability has an effect on Thai social stability. For this reason, the traditional identity of Thai Likay performance should be conserved to ensure that the identity of Thai lifestyle can be preserved at the same time (Pibulyakij, 1998).

\section{Conclusion}

Likay in Thailand originated as an old Islamic religious activity that was imported into Thailand during the Ayutthaya era. This show was changed and modified by Thai culture and became a kind of Thai acting performance. Likay is very famous in Central Thailand and there are more than six hundred Likay troupes in the area. Most of them also conserve the traditional traits and identities of Thai Likay very well, even if some things have been changed over time. The nine important components of Likay performance are: ritual and belief, Likay stage setting, standard Likay music bands, skillful performers, specific costumes, interesting drama, authentic songs, good language poems, and suitable dancing.

The researcher found that the current problems of Likay performance in Central Thailand can be classified into three groups. The first group is the problem with performers, such as a lack of professional performers and the development of future generations. The second group concerned the nine components of Likay performance, such as a lack of interest, ignorance of traditional rituals, lack of common language and poor audiences support. The final group concerned troupe management, such as poor support by communities and local governors. For 
these reasons, the researcher tried to discover an approach to Likay performance development. So, the patterns of Likay development must cover every problem. These approaches should lead to increased economic, social and cultural value of Thai Likay performances. Finally, Likay performances should be promoted to be a part of the national, cultural heritage as soon as possible.

The development pattern of Likay performance to add economic, social and cultural value should be started by the local government and community. Likay troupes should upgrade themselves to be community businesses and make more money for their own community. Likay should be supported and conserved by the community and Likay performers should be good role models for the next generation. More creativity and morality should be included in the Likay shows. At the same time, the nine components of Likay performance should be upgraded and developed.

\section{References}

Adulpan, K. Sornmanee, C., \& Srihong, C. (1978). Fundamentals of Governmental Administration. Bangkok: Ramkamhang University.

Anthony, W. (1966). Religion: An Anthropology View. New York: Random House.

Bentz, V. M., \& Shapiro, J. J. (1998). Mindful Inquiry in Social Research. New York: Sage.

Boas, F. R. (1966). Language and Culture. New York: The Free Press.

Bohannan, P., \& Glozer, S. (1973). Hi points in Anthropology. New York: Alfred A. Knopt.

Boonjaruen, K. (1979). Encyclopedia of Philosophy. Bangkok: Thai Wattanapanich.

Branett, H. G. (1953). Innovation: The Basis of Cultural Change. New York: McGraw-Hill.

Brockett, O. G. (1974). History of the Theatre (2nd ed.). Boston: Allyne and Bacon.

Brown, D. H. (1980). Principles of Language Learning and Teaching. New Jersey: Prentice-Hall.

Cernea et al. (1985). Putting People First: Sociological Variables in Development Projects. Baltimore: The Johns Hopkins University Press.

Chamber, E. (1985). Applied Anthropology: A Practical Guide. New Jersey: Prentice-Hall.

Chumchengrak, W. (1989). Likay. Bangkok: Srinakharinwirot Prasanmit University.

Clifford, G. (1973). The Interpretation of Culture. New York: Basic Books.

Conrad, P. K. (1978). Cultural Anthropolog. New York: Random House.

David, B. (1968). Theoretical Anthropology. New York: Columbia University Press.

Denzin, N. K. (1970). Sociological Methods: A Source Book. Chicago: Aldine.

Disakul, S. (1963). Art in Thailand. Bangkok: Thammasat University.

Duncan, C. M. (1981). A New Dictionary of Sociology. London: Roulle Kegan Paul.

Edward, T. (1871). Primitive Culture. New York: Macmillan.

Everett, M. R. (1976). Social Change in Rural Society. New York: Appleton Century Crafts.

Kachaprasert, J. (2000). Likay. Bangkok: Srinakharinwirot Prasanmit University.

Natsupa, C. (2004). Background and Context of Social Culture Paradigm. Bangkok: Community Organizations Development Institute (Public Organization).

Natsupa, C., \& Lertwicha P. (1994). Thai Community's Culture. Bangkok: Community Organizations Development Institute.

Patyaiaing, P. (1998). Aesthetics. Bangkok: Wattana Panich.

Pibulyakij, N. (1998). Likay. Bangkok: Compact Print.

Posakrisana, P., \& Udompol, S. (1979). Literatures composed in Likay performance. Bangkok: The Prime Minister's Office.

Pramote, K. (1969). Likay Thai Performance and Music. Bangkok: Thammasat University.

Santasombat, Y. (1997). Human and Culture. Bangkok: Thammasat University.

Satsanguan, N. (1996). Anthropological Research. Bangkok: Chulalongkorn University.

Sirikaya, N. (1982). Doo Nang Doo Lakorn. Bangkok: Chulalongkorn University. 
Udompol et al. (1979). Literature composed in Likay performance. Bangkok: Guru Sapa Publisher.

Wannasiri, N. (1997). Anthropology Social and Culture. Bangkok: Thammasat University. 